\title{
GESTÃO DOS RESÍDUOS DA CONSTRUÇÃO CIVIL: ANÁLISE DA LEGISLAÇÃO MUNICIPAL DE GUANAMBI - BA
}

\author{
Thomas Leonardo Marques de Castro Leal ${ }^{1}$ \\ Naira de Lima Silva² \\ Luísa Magalhães de Araújo³
}

\begin{abstract}
RESUMO
O setor da construção civil colabora positivamente com o crescimento econômico e geração de empregos diretos e indiretos. Todavia, o crescimento desse setor também gera passivos. Em virtude disso, tem crescido a preocupação com os resíduos de construção e demolição gerados, os quais são classificados de acordo com suas características, de modo a facilitar seu gerenciamento. O estudo busca analisar a legislação municipal de Guanambi que dispõe sobre o gerenciamento dos resíduos sólidos da construção civil, verificando sua adequação em relação à legislação nacional e como vem acontecendo a gestão dos resíduos no município. Para isso foram analisadas a legislação municipal, referente ao gerenciamento desses resíduos frente à sua prática, avaliada através de agentes envolvidos e observação de pontos de destinação final. Nota-se que as diretrizes impostas nas leis municipais não são suficientes para cumprir o que preconiza a Resolução Conama n 307/2002 e a Política Nacional de Resíduos Sólidos, e nem suficiente para sensibilizar os geradores. Ademais, o Plano Municipal Integrado de Gestão de Resíduos Sólidos, ainda que inclua o Plano Municipal de Gerenciamento de Resíduos da Construção Civil em seu texto, não contempla os requisitos estabelecidos pela PNRS. Assim, as ações do poder público têm sido incipientes e o arcabouço legislativo tem um caráter mais normativo, não direcionando para o desempenho em prol de edificações de menor impacto ambiental.
\end{abstract}

Palavras-chave: Gerenciamento; PMGIRS; Resíduos Sólidos.

\footnotetext{
1 Doutorando em Desenvolvimento e Meio Ambiente pela Universidade Estadual de Santa Cruz (UESC) e pesquisador do Observatório UniFG do Semiárido Nordestino. e-mail: thomasmdcl@gmail.com

2 Mestra em Geotecnia pela Universidade Federal de Ouro Preto (UFOP) e docente na Universidade Federal do Sul da Bahia (UFSB). E-mail: nls.naiara@gmail.com

${ }^{3}$ Mestra em Meio Ambiente, Aguas e Saneamento pela Universidade Federal da Bahia (UFBA) e docente do Centro Universitário UniFG. E-mail: luisamagalhaesaraujo@gmail.com
} 


\title{
CONSTRUCTION WASTE MANAGEMENT: ANALYSIS OF MUNICIPAL LEGISLATION OF GUANAMBI-BA
}

\begin{abstract}
The civil construction sector collaborates positively with economic growth and the generation of direct and indirect Jobs. However, the growth of this sector also generates liabilities. As result, there has been a growing concern about the construction and demolition waste generated, which are classified according to their characteristics, to facilitate their management. This paper aims to analyze the municipal legislation of Guanambi that provides for the management of solid waste from construction, checking its adequacy in relation to the national legislation, and how the waste management in the municipality has been happening. For this, the municipal legislation related to the management of these wastes were analyzed in relation to their practice, evaluated through agents involved and observation of final destination points. It is noted that the guidelines imposed by municipal laws are not sufficient to comply with the provisions of National Environment Council, Resolution 307/2002, and National Solid Waste Policy (PNRS), nor sufficient to sensitize generators. In addition, the Integrated Municipal Solid Waste Plan (PMIGRS), even if it includes the Municipal Plan of Construction Waste Management in its text, does not include the requirements established by PNRS. Thus, the actions of the public power have been incipient, and the legislative framework has a more normative character, not directing the performance in favor of buildings with less environmental impact.
\end{abstract}

Key words: Management; PMIGRS; Solid Waste.

\section{1- INTRODUÇÃO}

A cadeia produtiva da construção civil, que envolve também a Indústria e Comércio de Materiais de Construção, Indústria de Equipamentos e Serviços, tem assumido importância cada vez maior para a economia brasileira (FIRJAN, 2014). Ainda segundo a entidade, a cadeia produtiva é composta por diversas áreas com grande poder empregatício, utilizando desde a mão-de-obra qualificada até os profissionais menos capacitados, assegurando grande percentual da participação do setor na economia brasileira, aumentando a quantidade de pessoas com poder aquisitivo para movimentá-la (FIRJAN, 2014).

Embora o setor colabore positivamente para economia no país, a cadeia produtiva da construção civil tem causado impactos ambientais negativos, desde a exploração de agregados para a produção de insumos, até o desperdício de matéria 
prima e grande geração de resíduos. A Resolução n 001/1986 do Conselho Nacional de Meio Ambiente (CONAMA) define impacto ambiental como "qualquer alteração das propriedades físicas, químicas e biológicas do meio ambiente, causada por qualquer forma de matéria ou energia, direta ou indiretamente, resultante das atividades humanas". (CONSELHO NACIONAL DE MEIO AMBIENTE, 1986).

Além do intenso consumo de recursos naturais, os grandes empreendimentos de construção provocam alteração da paisagem e, como todas as demais atividades da sociedade, geram resíduos (IPEA, 2012). A perda de materiais sob forma de resíduos, ou sob outra condição, representa o desperdício de matérias primas e isto faz com que a indústria da construção civil seja foco nas discussões pela busca de um desenvolvimento sustentável (SOUSA et al., 2004). Vieira et al. (2019), em um estudo com 15 obras, verificou uma geração de, aproximadamente, $90 \mathrm{~kg} / \mathrm{m}^{2}$, na fase de acabamento.

De acordo com a Associação Brasileira de Empresas e Limpeza Pública e Resíduos Especiais, em 2019 foram gerados cerca de 45 milhões de toneladas de resíduos provenientes de construção e demolição (RCD), quantidade que em unidade per capita corresponde aproximadamente a $213 \mathrm{~kg} / \mathrm{hab} / \mathrm{ano}$ (ABRELPE, 2020).

Os RCDs correspondem em massa a uma taxa de aproximadamente $61,21 \%$, cerca de 44 milhões de toneladas, dos resíduos sólidos urbanos (RSU) produzidos nas cidades brasileiras (ABRELPE, 2020). Conforme explica a Bessa, Mello e Lourenço (2019), esses dados podem ser subestimados pois a maioria dos municípios brasileiros coletam apenas os resíduos descartados em vias públicas.

De acordo com o Ministério do Meio Ambiente (BRASIL, 2005), os RCDs representam um grande desafio para os municípios e órgãos estaduais no que se refere ao seu gerenciamento. Para a maior parte das cidades brasileiras este gerenciamento limita-se apenas à correção de despejos irregulares que, apesar de minimizar parte dos problemas, ainda está longe de ser uma solução ideal (MORAIS, 2006).

Os resíduos produzidos pelo setor são depositados em locais irregulares, como encostas de rios, vias públicas, terrenos baldios e aterros ilegais. Desse modo, além de comprometerem a paisagem e a harmonia dos centros urbanos, atraem a 
disposição de outros tipos de resíduos que propiciam a multiplicação de vetores biológico proliferadores de doenças e também trazem prejuízos ao município (KARPINSKI et al., 2008; PINTO, 1999).

Com o progresso do setor no início da década de 2000 houve um aumento do percentual de RCD nos centros urbanos, promovendo uma sobrecarga nos sistemas de limpeza municipais e, consequentemente, o acúmulo e descarte em locais inapropriados (IPEA, 2012). Bessa, Mello e Lourenço (2019) ressaltam que esta situação permanece até os dias atuais e que as deposições irregulares de RCD podem ser notadas no alto custo de limpeza urbana, pelas administrações municipais, devido ao descarte irregular.

O CONAMA publicou em 5 de julho de 2002 a Resolução № 307 que estabelece diretrizes, critérios e procedimentos para a gestão dos resíduos da construção civil, além de disciplinar as ações necessárias de forma a minimizar os impactos ambientais.

Tal resolução define como RCD todos aqueles provenientes de construções, reformas, reparos e demolições de obras e os resultantes da preparação e da escavação de terrenos. Estes resíduos são ainda classificados, para efeito desta resolução e conforme a Resolução do CONAMA № 431/2011, da seguinte maneira:

- Classe A: resíduos reutilizáveis ou reciclados como agregados;

- Classe B: resíduos recicláveis para outras destinações, tais como plásticos, papel, papelão, metais, vidros, madeiras, embalagens vazias de tintas imobiliárias e gesso;

- Classe C: resíduos para os quais não foram desenvolvidas tecnologias ou aplicações economicamente viáveis que permitam a sua reciclagem ou recuperação;

- Classe D: resíduos perigosos oriundos do processo de construção.

A resolução determina ainda que os $\mathrm{RCDs}$ devem ser destinados de acordo com sua classe. Ademais, visando a redução da quantidade de resíduos produzidos e o seu correto gerenciamento, estabelece obrigações para os geradores e para os municípios. 
Outro marco importante para o gerenciamento de RCD, em âmbito nacional, foi a aprovação da Política Nacional de Resíduos Sólidos (PNRS) - Lei Federal oㅜ 12.305 de 2 de agosto do ano de 2010. Esta dispõe sobre os princípios, objetivos e instrumentos, bem como sobre as diretrizes relativas à gestão integrada e ao gerenciamento de resíduos sólidos, incluindo os resíduos da construção civil, as responsabilidades dos geradores e do poder público e os instrumentos econômicos aplicáveis.

Um dos princípios desta Lei é que os geradores devem dar prioridade à não geração de resíduos e, secundariamente, à redução, reutilização, reciclagem e destinação final. Estes são responsáveis pela implantação de programas de gerenciamento de RCD nos seus empreendimentos, estabelecendo procedimentos necessários para o manejo e destinação adequada dos resíduos (CONSELHO NACIONAL DE MEIO AMBIENTE, 2002).

Para os municípios, a resolução determina que estes devem elaborar o Plano Integrado de Gerenciamento de Resíduos da Construção Civil. Assim, os gestores municipais e as empresas construtoras necessitam adaptar seus processos de modo a garantir a destinação ambientalmente correta dos RCD (CONSELHO NACIONAL DE MEIO AMBIENTE, 2002).

Nesse contexto, este trabalho tem como objetivo analisar a legislação municipal de Guanambi que dispõe sobre o gerenciamento dos resíduos sólidos da construção civil, verificando sua adequação em relação à legislação nacional e como vem acontecendo a gestão dos resíduos no município.

\section{2- METODOLOGIA}

De acordo com o IBGE (2010), o município de Guanambi, localizado no centrosul baiano (Figura 1), ocupa uma área de $1.272,367 \mathrm{~km}^{2}$ e possui uma população estimada em 78 mil habitantes. A cidade é polo de atração regional, referência para mais de 50 municípios situados nas microrregiões da Serra Geral, Médio São Francisco, Oeste e Sudoeste da Bahia e o extremo norte de Minas Gerais. 


\section{¿UNISUl}

Figura 1 - Localização da cidade de Guanambi.

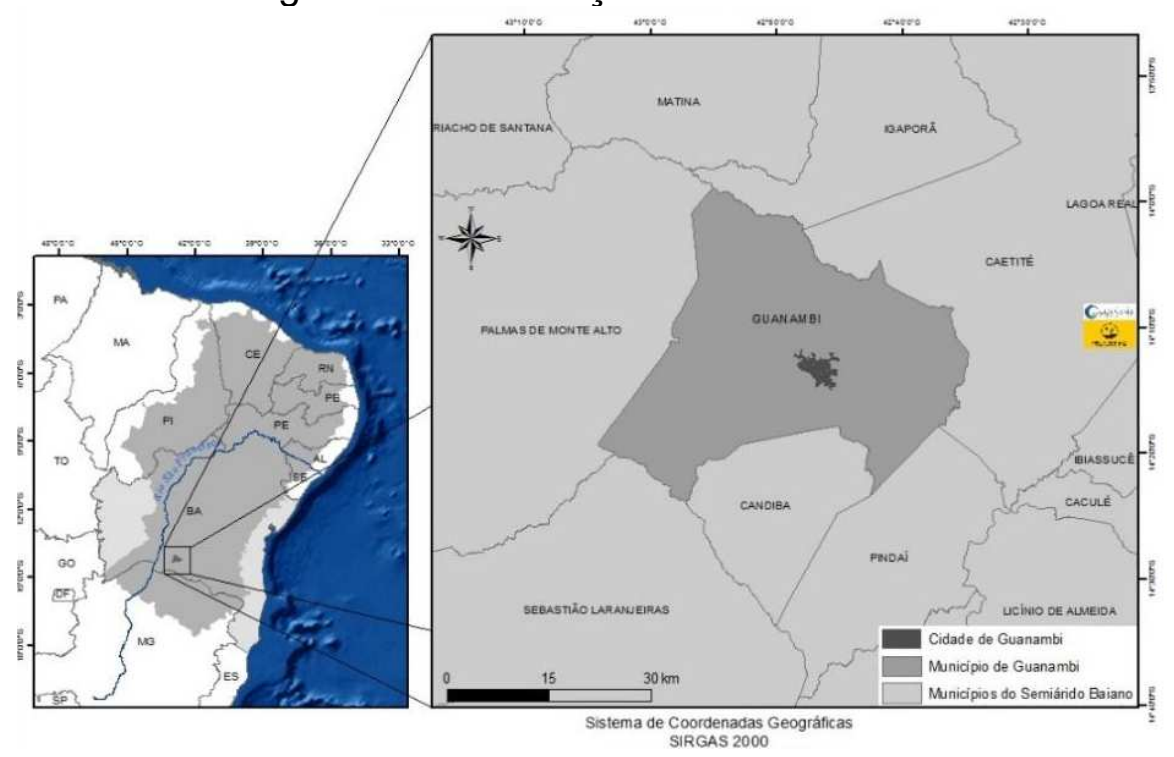

Fonte: IBGE, 2010.

Org. Campos, Pablo Kristian Trindade, 2017.

Para atingir o objetivo proposto, analisou-se as legislações que versam sobre o gerenciamento dos resíduos sólidos de construção e demolição no município, entre 2000 e 2020. Foi realizada uma discussão sobre as legislações vigentes e sua adequação às Legislações Federais.

Em seguida, avaliou-se a gestão municipal RCD. Essa avaliação foi realizada através do levantamento de dados secundário (documentos oficiais) e entrevistas com os agentes envolvidos na gestão municipal de Guanambi. Estas entrevistas foram realizadas com técnicos responsáveis da Secretaria de Agricultura e Meio Ambiente e da Secretaria de Infraestrutura.

Por fim, avaliou-se a destinação final destes resíduos por meio de dados obtidos através de análise de documentos e observações in loco e um registro fotográfico realizado para demonstração propositiva do assunto.

\section{3- RESULTADOS E DISCUSSÃO}

O poder público de Guanambi tem avançado na elaboração de legislações que contemplem a gestão integrada dos resíduos gerados no município. Dessa forma, foram analisadas as leis que dispõem sobre a gestão dos resíduos, conforme o 
Quadro 1 a seguir. Os resultados estão organizados de forma a discutir cada legislação separadamente, verificando sua conformidade.

Quadro 1 - Legislação municipal avaliada

\begin{tabular}{|l|l|}
\hline Lei & Disposição \\
\hline $\begin{array}{l}\text { Lei Municipal } \\
n^{\circ} 839 / 2014\end{array}$ & $\begin{array}{l}\text { Institui o Plano Municipal Integrado de Gerenciamento de } \\
\text { Resíduos Sólidos }\end{array}$ \\
\hline $\begin{array}{l}\text { Lei Municipal } \\
n^{\circ} 853 / 2014\end{array}$ & $\begin{array}{l}\text { Dispõe sobre o uso de caçambas estacionárias nas vias e } \\
\text { logradouros públicos para remoção de entulhos provenientes } \\
\text { da construção civil }\end{array}$ \\
\hline $\begin{array}{l}\text { Lei Municipal } \\
\text { no 1.206/2018 }\end{array}$ & $\begin{array}{l}\text { Dispõe sobre a coleta, transporte e destinação final dos } \\
\text { resíduos de construção civil e entulhos de qualquer natureza }\end{array}$ \\
\hline
\end{tabular}

Fonte: Autores, 2018.

\section{1- PLANO MUNICIPAL INTEGRADO DE GERENCIAMENTO DE RESÍDUOS}

A PNRS determina que, no escopo do gerenciamento integrado, deve-se contemplar, direta ou indiretamente, as etapas de coleta, transporte, transbordo, tratamento e destinação final ambientalmente adequada dos resíduos sólidos, exigidos na forma da Lei (BRASIL, 2010a).

Assim, o Plano Municipal Integrado de Gerenciamento de Resíduos Sólidos (PMIGRS) - Lei no 839 de 12 de junho de 2014 é um dos instrumentos previstos na Lei Federal n 12.305/2010. Sua função é nortear o desenvolvimento das atividades voltadas para o manejo adequado de resíduos em todo Município. O item 9 do Plano Municipal discorre sobre o manejo de resíduos de construção e demolição. Este item traz o conceito de RCD, quais os seus impactos ambientais e, em seu último parágrafo, traz o seguinte texto:

Nesse sentido, deve-se promover, ou incentivar, políticas públicas que levem
à conscientização e preparação do setor produtivo (empresas construtoras e
coletoras de entulho) por meio da implantação de procedimentos que
viabilizem a coleta seletiva de resíduos sólidos nos canteiros de obras, assim
como seja instituído um aparato jurídico, que permita a elaboração e
implantação dessas políticas e que levem à minimização da quantidade de
RCD gerado. (GUANAMBI, 2014a).

A PNRS, em seu Art. 19, trata das diretrizes para os planos municipais, traçando o conteúdo mínimo destes. Ao analisar tais diretrizes e texto do PMIGRS é possível destacar o que não está adequado no Plano Municipal em relação à Política 
Nacional. O Quadro 2 abaixo estabelece quais as conformidades e não conformidades do PMIGRS em relação ao gerenciamento dos RCD.

Quadro 2 - Conformidade do PMIGRS em relação ao Art. 19 da PNRS

\begin{tabular}{|l|l|}
\hline Item da Política Nacional de Resíduos Sólidos & Conforme \\
\hline $\begin{array}{l}\text { I - diagnóstico da situação dos resíduos sólidos gerados no } \\
\text { respectivo território, contendo a origem, o volume, a } \\
\text { caracterização dos resíduos e as formas de destinação e } \\
\text { disposição final adotadas; }\end{array}$ & Não \\
\hline $\begin{array}{l}\text { IV - identificação dos resíduos sólidos e dos geradores sujeitos } \\
\text { a plano de gerenciamento específico de que trata art. 20 ou o } \\
\text { sistema de logística reversa na forma do art. 33, observadas as } \\
\text { disposições desta lei e de seu regulamento, bem como as } \\
\text { normas estabelecidas pelos órgãos do Sisnama e do SNVS }\end{array}$ & Não \\
\hline $\begin{array}{l}\text { VIII - definição das responsabilidades quanto à sua } \\
\text { implementação e operacionalização, incluídas as etapas do } \\
\text { plano de gerenciamento de resíduos sólidos a que se refere o } \\
\text { art. } 20 \text { a cargo do poder público; }\end{array}$ & Não \\
\hline $\begin{array}{l}\text { XIV - metas de redução, reutilização, coleta seletiva e } \\
\text { reciclagem, entre outras, com vistas a reduzir a quantidade de } \\
\text { rejeitos encaminhados para disposição final ambientalmente } \\
\text { adequada; }\end{array}$ & Não \\
\hline $\begin{array}{l}\text { XVI - meios a serem utilizados para o controle e a fiscalização, } \\
\text { no âmbito local, da implementação e operacionalização dos } \\
\text { planos de gerenciamento de resíduos sólidos de que trata o art. } \\
20 \text { e dos sistemas de logística reversa previstos no art. 33. }\end{array}$ & Não \\
\hline
\end{tabular}

Fonte: Autores, 2018.

Em relação ao diagnóstico da situação dos RCD, item I do Art. 19 da Lei oo 839/2014, Lima e Cabral (2013) afirmam que muitos destes resíduos são passíveis de reciclagem ou reutilização, mas que uma das etapas mais importantes, o estudo de caracterização e composição física, não é realizada. Estes estudos podem interferir diretamente nos resultados dos processos de reciclagem/reutilização. O processo de caracterização estima ainda a classificação e quantidade gerada conforme classificação da CONAMA n 307/2002.

No item IV, entende-se por geradores de resíduos da construção civil o proprietário do imóvel, ou do empreendimento, e de seus contratados. O princípio da 
responsabilidade compartilhada, previsto na Lei Federal n 12.305 (BRASIL, 2010a), estabelece que todas as partes envolvidas no ciclo de vida dos produtos possuem encargo de minimizar o volume de resíduos sólidos e rejeitos gerados, bem como para reduzir os impactos causados à saúde humana e à qualidade ambiental. Assim, identificar os geradores dos RCD é essencial para traçar as ações necessárias para uma gestão adequada.

No item IV, entende-se por geradores de resíduos da construção civil o proprietário do imóvel, ou do empreendimento, e de seus contratados. O princípio da responsabilidade compartilhada, previsto na Lei Federal n 12.305 (BRASIL, 2010a), estabelece que todas as partes envolvidas no ciclo de vida dos produtos possuem encargo de minimizar o volume de resíduos sólidos e rejeitos gerados, bem como para reduzir os impactos causados à saúde humana e à qualidade ambiental. Assim, identificar os geradores dos RCD é essencial para traçar as ações necessárias para uma gestão adequada.

Segundo a PNRS (BRASIL, 2010a), empresas de construção civil devem desenvolver seus próprios planos de gerenciamento. O poder público deve indicar as áreas favoráveis para a disposição dos rejeitos dos geradores, sujeitos ao plano de gerenciamento específico. Oferecer a rede de coleta e destinação ambientalmente correta somente para os pequenos geradores, responsáveis por reformas e autoconstruções e incapazes de implementar a autogestão. Contudo, o texto do Plano Municipal não traz nenhuma destas informações.

Baptista Júnior e Romanel (2013), por exemplo, perceberam que os resíduos de pequenas obras representam uma parcela que ultrapassa $50 \%$ do total de resíduos de construção civil gerados na cidade do Rio de Janeiro. Ou seja, não apenas as grandes empresas devem ser fiscalizadas, mas as pequenas obras também. Em entrevista, um dos responsáveis técnicos da Secretaria de Agricultura e Meio Ambiente diz que devido à grande expansão da área urbana e o baixo efetivo de funcionários a fiscalização tem se tornado cada vez mais difícil.

A Lei Municipal no 1.107/2017, que institui o Sistema Municipal de Meio Ambiente, define em seu Anexo I a tipologia dos empreendimentos passíveis de licença ambiental. "Serviços de Britagem, Resíduos da Construção Civil e Outros" são 
classificados como nível 1, cabendo ao poder público municipal realizar o processo de licenciamento. Um dos documentos necessários para concessão da licença é o Programa de Gerenciamento Resíduos Sólidos (PGRS), estabelecido como uma das diretrizes da PNRS (BRASIL, 2010b; MAFFESDONI; FERNANDES, 2019). Neste documento devem constar como conteúdo mínimo, a descrição do empreendimento ou atividade; diagnóstico dos resíduos sólidos gerados; origem e volume dos resíduos; e procedimentos operacionais relativos às etapas do gerenciamento. Apesar da obrigatoriedade, estabelecida na PNRS, os geradores de resíduos de construção civil não precisam realizar o licenciamento ambiental no município, de acordo com a legislação municipal, conforme relatou o responsável pelo licenciamento municipal.

Tratando-se das metas de redução, reutilização e reciclagem, os 3 R's, a legislação menciona a importância, mas não estabelece projetos, programas, responsabilidades ou ações para atingir tais metas. Em seu estudo, Costa et al. (2007) verificaram que algumas variáveis influenciam mais no sucesso de programas de reciclagem de RCD. Entre elas, os autores citaram a existência de programas de coleta seletiva de lixo, programas de incentivo para geração de trabalho e renda e existência de áreas de recepção de RCD como as mais importantes.

Em relação à disposição final dos resíduos de construção civil, o item 8.1 do PMIGRS afirma que: "Quanto aos resíduos inertes (resíduos de construção civil e terra), estes poderão ser utilizados como material de cobertura diária dos resíduos a serem dispostos" (GUANAMBI, 2014b). Contudo, de acordo com a Resolução Conama no 307/2002, em seu Art. $4^{\circ}$, as prefeituras são proibidas de receber os entulhos nos aterros sanitários municipais e cada município deve ter um plano integrado de gerenciamento com uma disposição final ambientalmente adequada deste resíduo.

De acordo com Monteiro (2001), no caso dos RCD, dentro da concepção de desenvolvimento sustentável estabelecida pela Agenda 21, reduzir os resíduos, utilizar subprodutos e beneficiar a quantidade de entulho gerado aparecem como tarefas fundamentais à sociedade atual. O conceito de rejeito, trazido pela PNRS, diz que todos os "resíduos sólidos que, depois de esgotadas todas as possibilidades de tratamento e recuperação por processos tecnológicos disponíveis e economicamente 
viáveis, não apresentem outra possibilidade que não a disposição final ambientalmente adequada" (BRASIL, 2010a). Assim, o tratamento ideal para os RCD é a reciclagem.

Utilizando uma metodologia semelhante, Sousa (2020) verificou que em relação ao local de disposição, através do levantamento de informações disponibilizadas no PMGIRS de Santarém, Pará, e as respostas obtidas das construtoras através dos questionários, foi possível encontrar incoerência de informações. Isso reforça que muitas cidades no Brasil tratam com precariedade a questão dos RSU e os municípios, a despeito de exigências legais, não se dão conta dessa problemática, com as ações para equacionarem e resolvê-la ficando aquém do desejado (BARROS; SILVEIRA, 2019).

\section{2- LEI MUNICIPAL No $853 / 2014$}

Guanambi possui ainda a Lei $n^{\circ} 853$ de 8 de julho de 2014, que dispõe sobre o uso de caçambas estacionárias nas vias e logradouros públicos para remoção de entulhos provenientes da construção civil. A Lei especifica como deve ser a caçamba quanto à sinalização, tamanho e cores, proibindo qualquer outra caçamba que não siga as especificações.

Perante a lei municipal é de responsabilidade do gerador a remoção e transporte do material em conformidade com as diretrizes do Departamento de Limpeza Urbana de Guanambi. O RCD deve ser destinado a um local pré-determinado pelo órgão responsável, ou deve-se contratar empresas particulares que são autorizadas pelo município para coleta dos mesmos (GUANAMBI, 2014b). A referida lei determina que a administração pública municipal, por meio da Secretaria Municipal Infraestrutura, indicará o local para depósito dos entulhos retirados, mediante pedido subscrito pelo representante legal da empresa, ou pelo particular. A colocação de entulhos em locais não autorizados implica na cassação da inscrição da empresa, sem prejuízo das medidas legais cabíveis para apreensão dos objetos e equipamentos utilizados no serviço. 
Conforme item IV da PNRS, partindo do princípio da responsabilidade compartilhada, empresas contratadas para deslocamento de resíduos da construção civil também se encaixam como geradores de resíduos sólidos, sendo assim obrigadas a realizar o processo de licenciamento e consequente PGRS (BRASIL, 2010a). Contudo, conforme explicou o responsável técnico da Secretaria de Agricultura e Meio Ambiente, as três empresas da cidade não possuem licença para operar.

Outra problemática está associada ao local para depósito do material retirado. A prefeitura não possui um controle do quantitativo de resíduos gerados no município, nem um local específico para depósito dos RCD. Ao observar os dados do Sistema Nacional de Informações sobre Saneamento - SNIS (BRASIL, 2019), que é base de dados em que são preenchidos dados sobre saneamento das mais de 5 mil cidades brasileiras, nota-se que a Secretaria de Infraestrutura preencheu os dados (Campos IN026 e IN027) e não informou o quantitativo geral ou per capita de geração de RCD.

Mesmo com essa Lei em vigor, a partir da sua data de publicação, proibindo outras formas de transporte e coleta de resíduos de construção civil, esse trabalho é realizado por autônomos denominados carroceiros. Ao verificar os dados preenchidos no SNIS pelo poder público local (Campo CC018), este respondeu que existem agentes autônomos que realizam a coleta.

\section{3- LEI MUNICIPAL No $1.206 / 2018$}

Recentemente, foi aprovada na Câmara Municipal de Guanambi a Lei № 1.206 de 30 de agosto de 2018 que dispõe sobre a coleta, transporte e destinação final dos resíduos de construção civil e entulhos de qualquer natureza (GUANAMBI, 2018).

Em seu Art 1을 a referida lei determina que as empresas responsáveis pela coleta, transporte e destinação final dos resíduos da construção civil recolhidos no município deverão informar à Secretaria de Infraestrutura o local de destinação final deste entulho, ainda que fora do território municipal. 
Esta informação deve indicar o volume aproximado, data e endereço completo do local de retirada, bem como a previsão de data e destino final, que deverá estar devidamente licenciado para a recepção do mesmo.

De acordo com a lei, constatada a irregularidade do local de destinação final do entulho, os infratores estarão sujeitos ao pagamento de multa no valor de um saláriomínimo vigente, ainda que verificada a regularidade do local da destinação final do entulho. $O$ veículo flagrado descartando qualquer tipo de material em local não licenciado para tal será multado pela autoridade municipal competente e recolhido ao pátio de apreensões, de onde só será liberado após o pagamento da multa e taxas devidas, e seu condutor levado ao órgão policial competente para a lavratura de boletim de ocorrência por crime ambiental.

No entanto, as empresas de coleta de RCD de Guanambi não cumprem a maioria das exigências estabelecidas pela legislação e destinam o material para as mais diversas áreas da cidade. As empresas consultadas, em sua totalidade, afirmaram que fornecem estes resíduos como material de aterro para terrenos, sendo o restante depositado no lixão da cidade. No entanto, não é realizado nenhum tipo de controle ou triagem do entulho para verificação da sua aplicabilidade como aterro.

Os RCD são extremamente heterogêneos, com grande variação das características e propriedades, compostos por materiais com potencial de reciclagem e outros tratados como resíduos perigosos, em decorrência do risco de contaminação. Para Boscov (2008), a variabilidade da composição dos RCD exige considerações especiais, quando utilizados em obras geotécnicas, como caracterização de cada lote, análise estatística de parâmetros ou estabelecimento de requisitos mínimos de aceitação.

Já o material depositado no lixão não cumpre a função de material de cobertura, como preconiza a Lei Municipal ํㅡ 839/2014, sendo misturado indiscriminadamente com os resíduos sólidos urbanos.

Segundo Marques Neto e Schalch (2010), como a quantidade de resíduos gerados por pequenas obras representam uma grande parcela do total do RCD, os planos municipais devem propiciar a criação de ações para a coleta desses pequenos volumes, fazendo com que os entulhos deixem de ser descartados em locais 
irregulares. A implantação de zonas de coleta de RCD para geradores de pequeno volume deve ser conduzida de modo que se abranja toda a área urbanizada com locais de entrega voluntária nos bairros, buscando atrair a maior parcela dos resíduos gerados (BRASIL, 2010b).

Em uma análise da usina de reciclagem de resíduos de construção civil (RCC) existente no município de Lages, os autores Strapassao et al. (2019) perceberam que não há dificuldade na venda do produto, e que a empresa possui clientes fixos que absorvem a maior parte da produção, reafirmando a aceitação do produto no mercado

\section{4- DISPOSIÇÃO FINAL}

De acordo Philippi Jr., Roméro e Bruna (2014) lixão é uma forma inadequada de disposição final de resíduos sólidos, que se caracteriza pela simples descarga do lixo sobre o solo, sem medidas de proteção ao meio ambiente ou à saúde pública.

Em 2014 encerrou o primeiro prazo para o cumprimento da Lei 12.305/2010, cujas metas estabelecem que os municípios acabem com estes lixões, além de investir em cooperativas de catadores e em parcerias para aumentar a coleta seletiva e a destinação adequada do lixo não reciclável (SAMPAIO et al., 2014). Entretanto, conforme ABRELPE (2020), apenas $40 \%$ dos municípios contam com aterros sanitários como forma de destinação final de seus resíduos. Apesar de ter assinado um Termo de Ajustamento de Conduta (TAC) junto ao Ministério Público em 2014, o município de Guanambi não se adequou aos termos da legislação, mantendo a forma de disposição inadequada.

O cumprimento do TAC refletiria na destinação adequada dos RCD. Todavia, conforme mostra a Figura 2, os RCD são depositados no lixão da cidade, misturados com outros tipos de resíduos, sem triagem adequada e sem nenhum controle ou fiscalização por parte dos órgãos responsáveis. Ocorre ainda a disposição irregular dos mesmos em vários pontos do município e a utilização como aterro ou regularização de terrenos (Figura 3).

Como os resíduos de construção e demolição são altamente heterogêneos, caso não haja a sua reciclagem, a Resolução CONAMA n 307 (CONSELHO 


\section{GESTÃO \& SUSTENTABILIDADE} AMBIENTAL

\section{¿UกISUl}

NACIONAL DE MEIO AMBIENTE, 2002) indica que os mesmos devem ser levados a aterros especializados em cada classe de resíduos.

Figura 2- Disposição irregular de RCD no lixão de Guanambi-BA

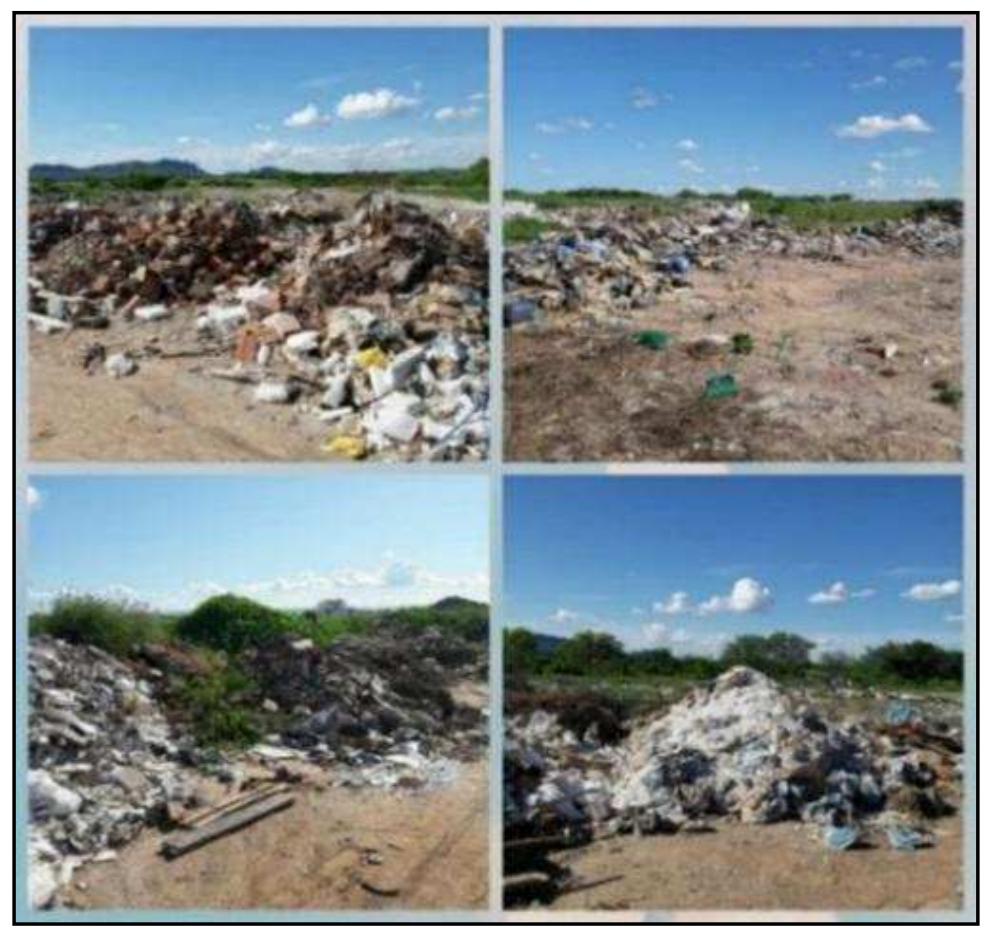

Fonte: Autores, 2018.

Figura 3 - Disposição irregular de RCD's e utilização de resíduos como aterro na Avenida Pref. José Neves Teixeira

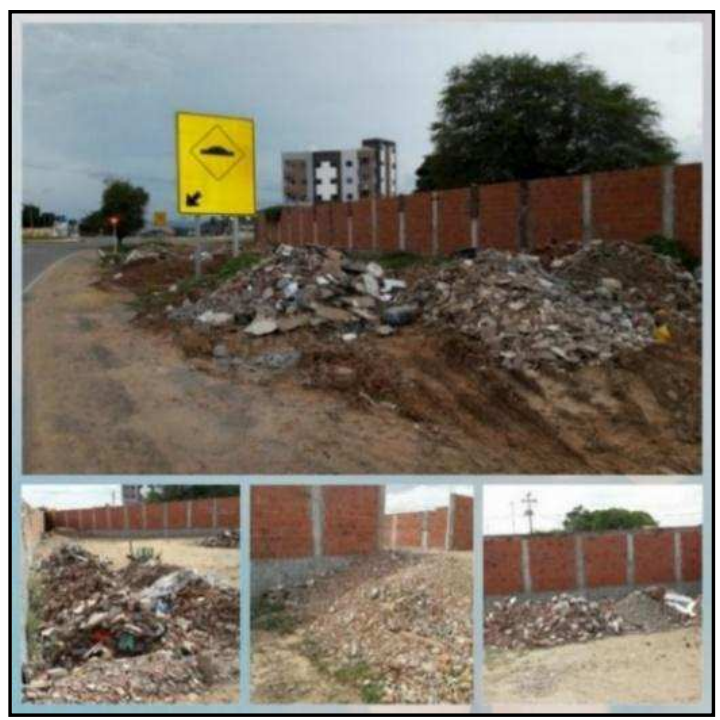

Fonte: Autores, 2018.

Revista Gestão e Sustentabilidade Ambiental., v. 10, n. 3, p. 154-173, jun. 2021. 


\section{4- CONCLUSÃO}

A partir das discussões percebe-se que as iniciativas por parte do poder público têm sido incipientes e o arcabouço legislativo tem um caráter mais normativo, não direcionando os empreendimentos para um descarte adequado dos resíduos. As diretrizes impostas nas leis municipais não são suficientes para cumprir o que preconiza a Resolução Conama n 307/2002 e a PNRS, e nem suficiente para sensibilizar os geradores.

O PMIGRS, ainda que inclua o Plano Municipal de Gerenciamento de Resíduos da Construção Civil em seu texto, não contempla os requisitos estabelecidos pela PNRS. Assim, o documento torna-se frágil em termos de planejamento e orientação sobre a disposição desses resíduos, consequentemente, a fiscalização a respeito do gerenciamento deles é deficiente.

Percebe-se a necessidade de um maior levantamento de dados sobre os geradores, no sentido de identificar, quantificar e caracterizar os resíduos gerados, para orientar o plano de gerenciamento desses resíduos. Ademais, é imprescindível a definição de uma área para recebimento do material descartado, de forma adequada.

O planejamento integrado do gerenciamento de resíduos é uma ferramenta importante, visto que inclui aspectos desde a formulação de políticas à elaboração do projeto técnico de soluções para o manejo e destinação deles. Tendo em vista a dificuldade envolvida na gestão de RCD, é necessário o envolvimento dos diferentes agentes do setor da construção, o incentivo e fiscalização do poder público, o desenvolvimento de pesquisa pelo meio acadêmico e a sensibilização da sociedade em geral.

Para pesquisas futuras, sugere-se realizar um estudo de composição gravimétrica e análise quantitativa dos RCD municipais a fim de avaliar quais as possibilidades de projetos efetivos de redução, reciclagem e/ou reutilização possam ser avaliados pelo poder público municipal.

\section{REFERÊNCIAS}

ABRELPE. Panorama dos resíduos sólidos no Brasil 2020. São Paulo: Abrelpe, 2020. Disponível em: https://abrelpe.org.br/panorama/. Acesso em: 20 dez. 2020. 
BAPTISTA JÚNIOR, Joel Vieira; ROMANEL, Celso. Sustentabilidade na indústria da construção: uma logística para reciclagem dos resíduos de pequenas obras. Revista Brasileira de Gestão Urbana, v. 5, n. 2, p. 27-37, jul./dez. 2013.

BARROS, Raphael Tobias de Vasconcelos; SILVEIRA, Áurea Viviane Fagundes. Uso de indicadores de sustentabilidade para avaliação da gestão de resíduos sólidos urbanos na Região Metropolitana de Belo Horizonte. Eng. Sanit. Ambient., v. 24, n. 2, p. 411-423, apr. 2019

BESSA, Sofia Araújo Lima; MELLO, Tiago Augusto Gonçalvez; LOURENÇO, Karen Katleen. Análise quantitativa e qualitativa dos resíduos de construção e demolição gerados em Belo Horizonte. Urbe. Revista Brasileira de Gestão Urbana, v. 11, e20180099, 2019. DOI: https://doi.org/10.1590/2175-3369.011.e20180099.

BOSCOV, Maria Eugênia Gimenez. Geotecnia Ambiental. São Paulo: Ed. Oficina de Texto, 2008.

BRASIL. Lei no 12.305, de 2 de agosto de 2010. Institui a Política Nacional de Resíduos Sólidos, altera a Lei n 9.605, de 12 de fevereiro de 1998 e dá outras providências. Brasília, DF: Presidência da República, 2010a. Disponível em: http://www.planalto.gov.br/ccivil_03/_ato2007-2010/2010/lei//12305.htm. Acesso em: 17 jul. 2019.

BRASIL. Ministério do Meio Ambiente. Áreas de manejo de resíduos da construção civil e resíduos volumosos. Brasília, DF: Ministério do Meio Ambiente, 2005. Disponível em: https://www.mma.gov.br/informma/item/3871-manual-reunerecomendacoes-para-manejo-de-residuos-da-construcao-civil. Acesso em: 17 jul. 2019.

BRASIL. Ministério do Meio Ambiente. Manual para implantação de sistema de gestão de resíduos de construção civil em consórcios públicos. Brasília, DF: Ministério do Meio Ambiente, 2010b. Disponível em https://antigo.mma.gov.br/cidades-sustentaveis/residuos-solidos/item/10333consorcios.html. Acesso em: 17 jul. 2019.

BRASIL. Ministério do Desenvolvimento Regional. Sistema Nacional de Informação sobre Saneamento. SNIS - Série Histórica. Brasília, DF: Ministério do Desenvolvimento Regional, 2019. Disponível em: http://app4.mdr.gov.br/serieHistorica/. Acesso em: 17 jul.2019.

CONSELHO NACIONAL DE MEIO AMBIENTE (Brasil). Resolução n. 307, 05 de julho de 2002. Estabelece diretrizes, critérios e procedimentos para a gestão dos resíduos da construção civil e dá outras providências. Diário Oficial da República Federativa do Brasil, Brasília, DF, 17 jul. 2002. Disponível em: https://www.mma.gov.br/estruturas/a3p/_arquivos/36_09102008030504.pdf. Acesso em: 17 jul. 2019. 
CONSELHO NACIONAL DE MEIO AMBIENTE (Brasil). Resolução n. 001, de 23 de janeiro de 1986. Dispõe sobre procedimentos relativos ao Estudo de Impacto Ambiental. Diário Oficial da União, Brasília, DF, 17 fev. 1986. Disponível em: http://www.siam.mg.gov.br/sla/download.pdf?idNorma=8902. Acesso em: 17 jul. 2019.

COSTA, Nébel da et al. Planejamento de programas de reciclagem de resíduos de construção e demolição no Brasil: uma análise multivariada. Revista Engenharia Sanitária, v. 12, n. 4, p.446-456, 2007. DOI: http://dx.doi.org/10.1590/S141341522007000400012.

FIRJAN. Construção Civil: desafios 2020. Rio de Janeiro: Firjan, 2014. Disponível em: http://www.firjan.com.br/construcao-civil/desafios.htm. Acesso em: 17 jul. 2019.

GUANAMBI. Lei Municipal no 839, de 12 de junho de 2014. Institui o Plano Municipal Integrado de Gerenciamento de Resíduos Sólidos - PMIGRS, e estabelece outras providências. Guanambi: Prefeitura Municipal, 2014b. Disponível em: http://www.guanambi.ba.gov.br/arquivos/151557201428071.pdf. Acesso em: 17 jul. 2019.

GUANAMBI. Lei Municipal no 853, de 8 de julho de 2014. Dispõe sobre o uso de caçambas estacionárias nas vias e logradouros públicos para remoção de entulhos provenientes da construção civil, na cidade de Guanambi e dá outras providências. Guanambi: Prefeitura Municipal, 2014a. Disponível em: http://www.guanambi.ba.gov.br/arquivos/151835201428071.pdf. Acesso em: 17 jul. 2019.

GUANAMBI. Lei Municipal no 1.206, de 8 de julho de 2018. Dispõe sobre a coleta, transporte e destinação final dos resíduos de construção civil e entulhos de qualquer natureza e dá outras providências. Guanambi: Prefeitura Municipal, 2018. Disponível em: http://www.guanambi.ba.gov.br/arquivos/151835201428071.pdf. Acesso em: 17 jul. 2019.

IBGE. Estimativa Demográfica 2017 - Guanambi. Rio de Janeiro: IBGE, 2017. Disponível em: https://cidades.ibge.gov.br/brasil/ba/guanambi/panorama. Acesso em: 17 jul. 2019.

IPEA. Diagnóstico dos resíduos sólidos da construção civil. Brasília, DF: IPEA, $2012 . \quad$ Disponível em: http://www.ipea.gov.br/portal/images/stories/PDFs/relatoriopesquisa/120911_relatori o_construcao_civil.pdf. Acesso em: 17 jul. 2019.

KARPINSKI, Luisete Andreis et al. Gestão de resíduos da construção civil: uma abordagem prática no município de Passo Fundo-RS. Estudos tecnológicos, v. 4, n. 2, p. 69-87, 2008. Disponível em: http://revistas.unisinos.br/index.php/estudos_tecnologicos/article/view/5494. Acesso em: 17 jul. 2019. 
LIMA, Adriana Sampaio; CABRAL, Antônio Eduardo Bezerra. Caracterização e classificação dos resíduos de construção civil da cidade de Fortaleza (CE). Eng. Sanit. Ambient., v. 18, n. 2, p. 169-176. DOI: https://doi.org/10.1590/S141341522013000200009.

MAFFESSONI, Daiana; FERNANDES, Eloisa Francisco. Situação da gestão de resíduos da construção civil: estudo de caso de Capão da Canoa, Rio Grande do Sul. Revista de Ciências Ambientais, v. 13, n. 2, p. 07-12, 2019. http://dx.doi.org/10.18316/rca.v13i2.4935.

MARQUES NETO, José da Costa; SCHALCH, Valdir. Gestão dos resíduos de construção e demolição: estudo da situação no município de São Carlos-SP, Brasil. Revista de Engenharia Civil, n. 36, p.41-50, 2010. Disponível em: http://www.civil.uminho.pt/revista/artigos/n36/Pag.41-50.pdf. Acesso em: 17 jul. 2019.

MONTEIRO, José Henrique Penido et al. Manual de Gerenciamento Integrado de resíduos sólidos. Rio de Janeiro: IBAM, 2001. Disponível em: http://www.resol.com.br/cartilha4/manual.pdf. Acesso em: 17 jul. 2019.

MORAIS, Greiceana Marques Dias de. Diagnóstico da deposição clandestina de resíduos de construção e demolição em bairros periféricos de Uberlândia: subsídios para uma gestão sustentável. 2006. Dissertação (Mestrado em Engenharia Civil) - Universidade Federal de Uberlândia, Uberlândia, 2006. Disponível em: http://repositorio.ufu.br/bitstream/123456789/14129/1/DiagnosticoDeposicaoClandest ina.pdf. Acesso em: 17 jul. 2019.

PHILIPPI JR, Arlindo; ROMÉRO, Marcelo de Andrade; BRUNA, Gilda Collet. Curso de gestão ambiental. Barueri,SP: Manole, 2014.

PINTO, Tarcísio de Paula. Metodologia Para a Gestão Diferenciada de Resíduos Sólidos da Construção Urbana. São Paulo, 1999. Tese (Doutorado em Engenharia Civil) - Escola Politécnica, Universidade de São Paulo, São Paulo, 1999. Disponível em: http://www.casoi.com.br/hjr/pdfs/GestResiduosSolidos.pdf. Acesso em: 17 jul. 2019.

SAMPAIO, Rubens de Jesus et al. A gestão de resíduos sólidos urbanos: impasses políticos, técnicos, legais e metodológicos. Revista Eletrônica do Mestrado em Educação Ambiental, v. 2014, p. 87-101, 2014. Disponível em: https://periodicos.furg.br/remea/article/view/3528. Acesso em: 17 jul. 2019.

SOUSA, Bianca Mesquita. Gestão de Resíduos da Construção Civil em Santarém Pará, Brasil: Realidades e Desafios. Revista Gestão \& Sustentabilidade Ambiental, v. 9, n. 1, p. 635-649, abr. 2020. DOI: http://dx.doi.org/10.19177/rgsa.v9e12020635649.

SOUZA, Ubiracira Espinelli Lemes de et al. Diagnóstico e combate à geração de resíduos na produção de obras de construção de edifícios: uma abordagem progressiva. Ambiente Construído, v. 4. n. 4, p.33-46, 2004. Disponível em: 


\section{sunisul}

https://seer.ufrgs.br/ambienteconstruido/article/view/3573/1978. Acesso em: 17 jul. 2019.

STRAPASSAO, Helena et al. Reciclagem de Resíduos da Construção Civil no Município de Lages, SC. Revista Gestão \& Sustentabilidade Ambiental, v. 8, n. 1, p. 713-729, abr. 2019. DOI: http://dx.doi.org/10.19177/rgsa.v8e12019713-729.

VIEIRA, Cidney Ribeiro et al. Análise dos fatores de influência e diagnóstico da gestão dos resíduos da construção civil (RCC) nos canteiros de obra da cidade do Recife-PE. urbe. Revista Brasileira de Gestão Urbana, v.11, e20180176, 2019. DOI: https://doi.org/10.1590/2175-3369.011.e20180176. 